\title{
CARACTERÍSTICAS FÍSICAS DE SEDIMENTOS E SOLOS DE DOIS LAGOS DE VÁRZEA NA AMAZÔNIA CENTRAL
}

\author{
Sávio José Filgueiras FERREIRA ${ }^{1}$, Klaus REICHARDT ${ }^{2}$, Sebastião Átila \\ Fonseca MIRANDA ${ }^{3}$
}

\begin{abstract}
RESUMO - O regime hidrológico de nivel de água baixo e alto torna as várzeas suscetiveis a alterações ecológicas, tanto nos solos quanto nos lagos. No periodo de nivel de água alto, as várzeas são "fertilizadas" pelo sedimento em suspensão que é depositado, tornando essas áreas as mais férteis da Região Amazônica. O presente trabalho avalia as características de solos e de sedimentos de dois lagos de várzea (Passarinho e Gravetão, situados próximo a Manaus) no que tange às propriedades físicas como a textura e curvas de retenção de água. Os resultados revelam que os solos e os sedimentos têm alta capacidade de reter a água, e consequentemente de água disponível, com valores máximos da ordem de $45 \mathrm{~mm} / 10 \mathrm{~cm}$, considerando a água disponivel entre os potenciais $-10 \mathrm{e}$ $1500 \mathrm{kPa}$. A fração silte da composição granulométrica foi, na maioria dos resultados, a mais expressiva, variou de 17 a $71 \%$.
\end{abstract}

Palavras-chave: Várzea, solo, sedimento, textura, curva de retenção da água no solo.

Physical Characterizaton of 'Sediments and Soils of Two Lowland Lakes in Central Amazonia

ABSTRACT - The hydrologic regime, with high and low water levels make the low land very succeptible to ecological changes, in both soils and lakes. During high level periods, low land is "fertilized" by sediment deposition, making these areas the most fertile areas of the Amazonian region. This work is an evalution of soil and sediment characteristics of two low land lakes: Passarinho and Gravetão. They are situated near Manaus, Brazil. Parameters studied were: texture, and water retention. The results show that soils and sediments have high water retention properties, with maximum values around $45 \mathrm{~mm} / 10 \mathrm{~cm}$, considering the available water between -10 and $-1500 \mathrm{kPa}$. Silt is the main component in most samples, varying from 17 to $71 \%$.

Key-words: Low land, soil, sediment, texture, soil water retention curve.

\section{INTRODUÇÃO}

As várzeas da região amazônica são caracterizadas pela variação permanente nas suas formas e tamanhos devido à oscilação do nível d'água. Sua paisagem sofre constantes modificações. $\mathrm{Na}$ época de cheia ocorre um grande aumento de sua área inundada.

A ação da água na região tem um papel fundamental, caracterizado pelo regime hidrológico que, apesar da distribuição de chuva ser variada, é marcado por dois periodos: $o$ alto e o baixo nível das águas dos rios.

As características físicas, químicas e biológicas das águas superficiais na Amazônia refletem a geomorfologia dos sistemas de drenagem. Os rios que tem suas origens nos maciços das Guianas e do Brasil Central, têm geralmente as suas águas mais transparentes, com teores mais baixos de sais e de materiais em suspensão do que dos rios que têm suas nascentes na cordilheira dos Andes, como o Amazonas e o Madeira (Sioli, 1985).

O rio Amazonas transporta uma carga relativamente elevada de material

1 Coordenação de pesquisas em Geociências/CPGC, INPA, AM. PPG-CRHEA/EESC,USP,SP.

2 Depto de Física e Meteorologia/ESALQ e Centro de Energia Nuclear na Agricultura/CENA, USP, Piracicaba, SP. Cx. P. 9, CEP: 13416-970

3 Coordenação de pesquisas em Geociências/CPGC, INPA, AM. 
em suspensão e na época de cheia os seus valores são mais elevados (Meade et al., 1979). Nas várzeas esse material sedimenta-se parcialmente, pois a velocidade de corrente nessa área sofre uma diminuição. Nas grandes cheias, as águas dos lagos de várzea comunicamse com as águas do rio.

As águas barrentas do Amazonas quando penetram nas várzeas são freadas até quase a sua estagnação e o material em suspensão é depositado na planície aluvial. Desse modo as várzeas anualmente recebem camadas novas de sedimento fresco. Esse material depositável é relativamente rico em nutrientes e isso explica sua fertilidade e produtividade para a agricultura e a grande piscosidade dos lagos (Sioli, 1985).

As grandes flutuações do nível d'água produzem largas áreas de transição entre o sistema terrestre e o sistema aquático, provocando constantes mudanças nas condições ecológicas (Junk, 1980). Essas mudanças se dão devido ao caráter periódico do regime hidrológico. Alguns lagos chegam a secar no período de baixa precipitação pluviométrica. As várzeas, conforme Junk (1989), pertencem aos sistemas de inundação, que são dirigidos por um fator regular de perturbação, o pulso de inundação.

As várzeas da Amazônia faz parte das planícies de inundação, assim como o igapó. Essas planícies são formadas por sedimentos recentes (holocênicos) que se encontram pouco acima do nivel das águas e intermitentemente alagadas (Schubart, 1983). Ocupam uma área entre $50.000 \mathrm{a}$ $60.000 \mathrm{~km}^{2}$ de acordo com Sioli (1984), porém Junk (1995) informa que essa área é de $200.000 \mathrm{~km}^{2}$.
Nas várzeas ocorrem predominantemente solos com perfís pouco desenvolvidos, mal drenados, originados dos sedimentos fluviais recentes, designados como glei húmico e, de alta fertilidade química (Schubart, 1983), além de glei pouco húmico e os solos aluviais desenvolvidos nos diques marginais. Segundo Vieira \& Santos (1987)é possivel verificar a existência de diferença bastante ampla na textura destes solos, devido ao local de sua formação. Os que se aproximam das margens do rio Amazonas são normalmente siltosos e conforme se afastam para o interior, na direção dos lagos ou dos cursos d'água de menor volume, vão se tornando mais argilosos, o que é normal tendo em vista o diâmetro das partículas e a distância que são transportadas no processo de colmatagem.

Durante a vazante uma parte da vegetação flutuante é transportada das várzeas para o rio, porém a maior parte das plantas seca nas beiras e no fundo exposto dos lagos ( em torno de $10^{4} \mathrm{~kg}$ de matéria seca/há da área é coberta por plantas aquáticas). Essas plantas se decompõem, e os seus nutrientes podem ser aproveitados pela vegetação terrestre. Essas plantas aquáticas têm um papel importante na transferência de nutrientes e energia da fase aquática para a fase terrestre (Junk, 1980). Por esse motivo essas regiões podem ser aproveitadas com vantagem em empreendimentos agropecuários, devido aos produtos dessa decomposição.

O estudo das propriedades hidricas de solo e sedimento na região de áreas alagáveis, no caso, as várzeas da região amazônica, no que tange as 
características de retenção de água, textura e outros parâmetros físicos e quimicos é importante para o entendimento dos processos ecológicos entre o solo e os sistemas aquáticos, e para o uso destes solos para a agricultura. $\mathrm{O}$ solo apresenta interface com o ar atmosférico, é aerado, enquanto o sedimento é sempre imerso em água. No periodo chuvoso, com a inundação das várzeas, as áreas de solo diminuem. À medida que o nível d'água vai diminuindo, $\mathrm{a}$ área de solo vai aumentando.

Tanto solo quanto sedimento são porosos e são constituídos de três frações: sólida, liquida e gasosa. A fração sólida é denominada de matriz do solo. As frações liquida e gasosa correspondem ao espaço poroso. As interações entre a matriz do solo e a água ou solução do solo proporcionam o potencial mátrico e essas interações são forças associadas a capilaridade e adsorção, que promovem a retenção da água pelo material poroso.

$\mathrm{Na}$ agricultura o conhecimento da relação funcional entre o potencial mátrico da água no solo e sua umidade é fundamental na irrigação para que a água seja utilizada racionalmente, evitando o excesso e o déficit. Essa relação funcional é denominada de curva de retenção de água.

Além da importância na agricultura do estudo de propriedades fisicas de solos, são também na limnologia, pois o lago interage com sua bacia de drenagem. Segundo Odum (1988) a bacia hidrográfica inteira, e não somente a massa de água ou trecho de vegetação, deve ser considerada a unidade mínima de ecossistema, quando se trata de interesses humanos e essa unidade, quando utilizada para gerenciamento prático, deve incluir, para cada metro quadrado ou hectares de água, uma área de pelo menos 22 vezes maior de bacia de drenagem terrestre. Para Likens (1984) grande parte dos limnólogos tem ignorado a importância da rotina hidrológica nas ligações terra-água no regime do metabolismo e biogeoquímica de rios e lagos, havendo a necessidade do entendimento, pois essas ligações mostram intrincadas e complicadas interações entre terra-água.

Ribeiro (1991) estudou os dados de chuva para Manaus, desde 1911 até 1985, observou que a média anual de chuva foi de $2107 \mathrm{~mm}$. Informa que a estação chuvosa (dezembro-maio) teve precipitação média de $1546 \mathrm{~mm}$, enquanto que a estação mais seca (junhonovembro) apresentou média de $561 \mathrm{~mm}$. Nas várzeas durante o periodo de baixos indices de precipitação pluviométrica, grande área que antes encontravam-se inundadas, são utilizadas para práticas agrícolas. O emprego de plantas que apresentem raizes com baixa profundidade, nessa época, a camada do solo superficial pode apresentar baixo armazenamento d'água e, no caso de se pretender a irrigação, pode-se recorrer a instalação de tensiômetros, que fornecem o potencial matricial do solo e, indiretamente, com a curva caracteristica de retenção de água, estima-se a umidade do solo. Assim, a utilização desses solos podem tornar-se mais eficientes.

Para Junk (1995) a maior parte de "terra-firme" da Região Amazônica não pode suportar uma grande população humana com os sistemas de 
produção agricola que estão correntemente em uso; a maior capacidade de suporte existe em algumas áreas que apresentam um melhor suprimento de nutrientes, como as várzeas dos rios de águas brancas e essa capacidade de suporte pode ser ampliada pela melhoria dos sistemas agrícolas de produção.

O presente trabalho tem o objetivo de fornecer características das áreas de influência de dois lagos de várzea e de seus sedimentos, no que se refere às propriedades físicas, como textura e curvas de retenção de água. O estudo dos sedimentos deve-se ao fato de que na vazante o sedimento torna-se solo.

\section{MATERIAIS E MÉTODOS}

Foram estudados dois lagos de várzea. $\mathrm{O}$ lago Passarinho, localizado geograficamente entre os paralelos $3^{\circ} 13^{\prime}$ de latitude sul e $59^{\circ} 48^{\prime}$ de longitude Oeste de Greenwich. e o lago Gravetão entre os paralelos $3^{\circ} 13^{\prime}$ de latitude sul e 59 49' de longitude Oeste de Greenwich. Situam-se na ilha do Careiro, à margem esquerda do Paraná do Careiro, próximos a Manaus (Amazônia Central).

São considerados lagos pequenos, sem ligação com o rio Amazonas. O Passarinho possui aproximadamente 0,7 $\mathrm{km}$ de largura e $1,5 \mathrm{~km}$ de comprimento $\mathrm{e}$ o Gravetão $0,2 \mathrm{~km}$ e $0,85 \mathrm{~km}$, respectivamente. Os solos adjacentes aos lagos são utilizados para plantações de hortaliças, batata doce, mandioca e pastagens. As regiões litorâneas desses lagos são colonizadas por macrófitas aquáticas fixas e flutuantes.

Em cada local foram coletadas amostras num transecto perpendicular à margem do paraná do Careiro abrangendo áreas de solo e de lago, em época de nível de água baixa, onde a área da bacia de drenagem desses lagos era máxima, no dia 27/11/1991. As primeiras coletas foram realizadas no lago Passarinho.

\section{Amostragem de solo}

Foram obtidas amostras de solo em 7 pontos $(1,2,3,7,8,9$ e 10$)$, sendo 3 entre o lago e o paraná $(1,2$ e 3$)$ e 4 pontos do outro lado do lago $(7,8,9 \mathrm{e}$ 10), seguindo a linha do transecto indicado na (Fig. 1). A distância entre as coletas de amostras de solo no transecto foram de 50 metros, tendo como referência a linha da margem dos lagos. No lago Gravetão o mesmo procedimento de amostragem foi utilizado, mas as distâncias dos pontos de coleta 18,19 e 20 foram modificadas devido à diferença na morfologia dos sistemas amostrados. As distâncias entre os pontos 18,19 e 20 foram 100,70 e 80 metros, respectivamente.

\section{Amostragem de sedimento}

Dentro dos lagos foram escolhidas três estações de coleta: 2 próximas à zona litorânea ( 4 e 6$)$ e 1 no centro do lago (5). As profundidades dos pontos de coleta das amostras de sedimento nos lagos foram: lago Passarinho 2,7; 3,0 e 2,9 m, respectivo às estações 4,5 e 6 . No lago Gravetão 2,7; 3,0 e 3,1 m, respectivos aos locais de coleta 14,15 e 16.

Na coleta de amostras de solo, a superficie do solo foi escarificada e as amostras colhidas até a uma profundidade de $10 \mathrm{~cm}$. As amostras de sedimento foram obtidas por meio 


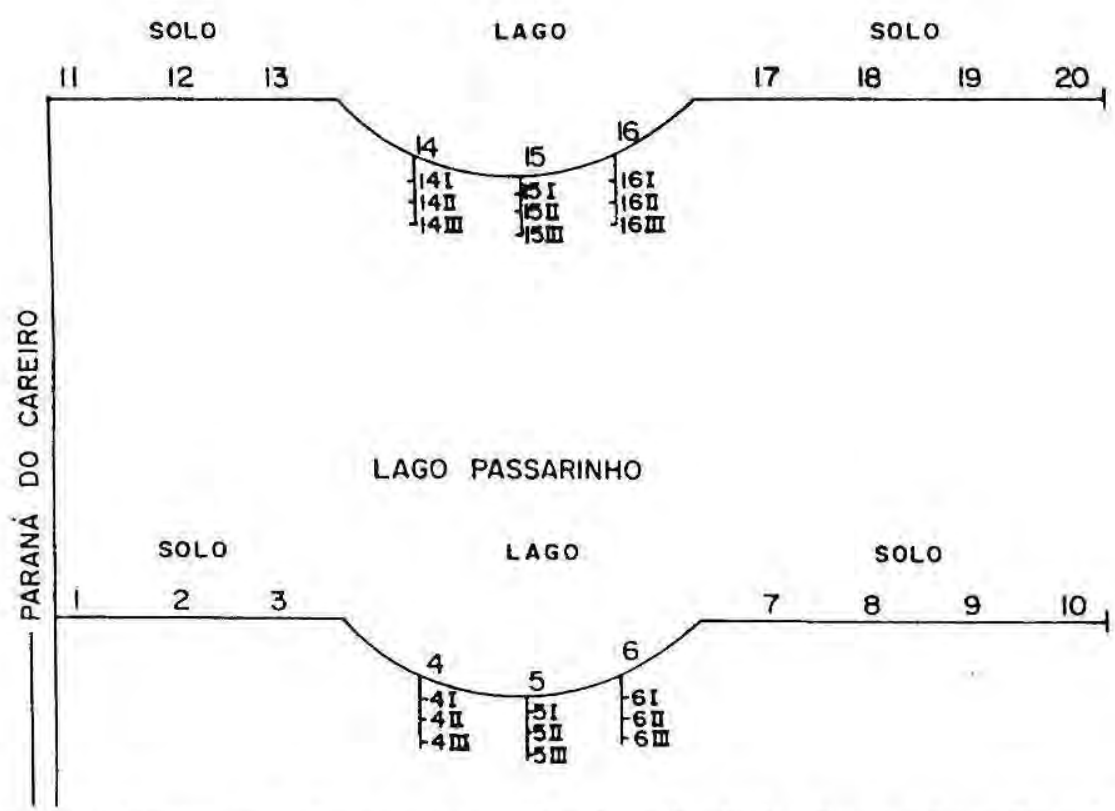

Figura 1. Representação dos transectos indicando os locais de coleta nos lagos Passarinho e Gravetão com seus respectivos números.

do coletor de sedimento tipo "core" vertical com um perfil de $50 \mathrm{~cm}$. As amostras de sedimento foram colhidas em triplicatas em cada estação para que o material fosse suficiente para as análises.

Cada amostra de sedimento foi dividida a cada $10 \mathrm{~cm}$ no perfil vertical, resultando 4 partes $(0-10,10-20,20-30$ e mais de $30 \mathrm{~cm})$. Em seguida foram colocadas em bandejas de teflon para secar à temperatura ambiente dentro do laboratório. Depois de secos, tanto o sedimento quanto o solo, foram pulverizados em graal, passados por peneira de $2 \mathrm{~mm}$.

Os números 4,5,6,14,15 e 16 na Figura 1 indicam os locais de coleta dentro do lago e como as suas amostras foram divididas em 4 partes, foram adicionados os índices I, II e III correspondendo às profundidades $10-20,20-30$ e mais de 30 $\mathrm{cm}$, respectivamente. As amostras da profundidade $0-10$ mantém o mesmo número do local de coleta.

\section{Curvas de Retenção de Água}

Cilindros (volume aproximado de $55 \mathrm{~cm}^{3}$ ) previamente preparados e pesados foram preenchidos com as amostras de solo e de sedimento para a obtenção de curvas de retenção de água. Estas foram obtidas por secamento, da forma clássica, dando-se ênfase a potenciais altos. Foram utilizadas os seguintes potenciais mátricos: $0,-1,-3 \mathrm{e}$ $8 \mathrm{kPa}$, em mesa de tensão. Depois as amostras seguiram para a câmara de Richards onde foram submetidas aos potenciais: $-30,-100,-500$ e $-1500 \mathrm{kPa}$, respectivamente. 
As amostras antes de serem submetidas aos potenciais mátricos, eram saturadas com água. Após cada equilíbrio, as amostras eram retiradas do aparelho e determinadas as massas por gravimetria. Depois das determinações, as amostras foram secas em estufa a 105-110 ${ }^{\circ} \mathrm{C}$, e determinadas as massas de sólidos. $O$ volume de poros total (porosidade total, $\phi)$ foi tomado como sendo a umidade è para $\theta$ potencial 0 (saturação).

Foi utilizado o Programa ("CURVARET", versão 2.11) de autoria de Van Lier \& Dourado Neto (1991) e conforme Dourado-Neto et al. (1990) para o ajuste das curvas de retenção, onde os potenciais ém foram relacionados com as umidades $\theta$ através do Modelo Matemático Empírico de Van Genuchten (1980). Esse Programa fornece valores aos parâmetros previstos nesse modelo e também um coeficiente de ajuste, que é o coeficiente de correlação $\left(r^{2}\right)$.

Van Genuchten (1980), propôs um modelo matemático empírico para ajustar a curva de retenção de água, em função do potencial mátrico como variável independente e da umidade à base de volume $\left(\mathrm{cm}^{3} / \mathrm{cm}^{3}\right)$ como variável dependente. $\mathrm{O}$ modelo matemático empírico proposto por Van Genuchten é dado pela equação (1):

$$
\theta=\theta_{r}+\frac{\left(\theta_{1}-\theta_{r}\right)}{\left[1+\left(\alpha\left|\psi_{m}\right|\right)^{n}\right]^{\beta}}
$$

Sendo: $\theta$ a umidade à base de volume $\left(\mathrm{cm}^{3} / \mathrm{cm}^{3}\right),\left|\Psi_{\mathrm{m}}\right|$ o módulo do potencial mátrico ( $\mathrm{cm}$ de água), $\theta_{\mathrm{r}}$ é a umidade residual $\left(\mathrm{cm}^{3} / \mathrm{cm}^{3}\right), \theta$ a umidade de saturação $\left(\mathrm{cm}^{3} / \mathrm{cm}^{3}\right), \alpha\left(\mathrm{cm}^{-1}\right.$ de água), $\beta$ e n são parâmetros empíricos obtidos do modelo pela regressão.

\section{Análise Granulométrica}

As frações do solo e de sedimento (argila, silte e areia) foram quantificadas através da técnica da atenuação da radiação gama. Esse novo método de análise mecânica do solo consiste na atenuação de um feixe de raios gama por uma solução em sedimentação, possuindo a vantagem de dar informação contínua sobre a distribuição das partículas. A atenuação do feixe de raios gama, para uma dada altura da sedimentação, varia ao longo do tempo, indicando a variação da concentração da suspensão (Vaz et al., 1992).

Cada amostra foi dispersa de modo tradicional, isto é, mecânica e quimicamente utilizando-se solução de hexametafosfato de sódio, de acordo com Manual de Métodos de Análise de Solo (EMBRAPA, 1979).

O sistema instrumental que foi utilizado é composto de uma fonte de 300 $\mathrm{mCi}$ de Am-241 e um espectrômetro gama monocanal para a medida da radiação. Para a obtenção dos valores das concentrações de argila, silte e areia (composição granulométrica), foi utilizada a seguinte equação (2):

$$
C=\frac{\ln \left(I^{\prime} / I\right) \cdot 10^{3}}{x\left(\mu_{p}-\mu_{a} / \rho_{p}\right)}
$$

Onde I I I' são as intensidades dos feixes emergentes e incidentes, respectivamente, $\mu_{\mathrm{p}}$ o coeficiente de atenuação das particulas do solo ou de massa e $\boldsymbol{\mu}_{\mathrm{a}}$ o coeficiente de atenuação da água. Foram determinados utilizando-se o mesmo sistema instrumental da atenuação gama (Vaz et al., 1992). A Densidade de Partículas $\left(p_{p}\right)$, foi determinada utilizando o método do 
balão volumétrico de acordo com (EMBRAPA, 1979).

\section{RESULTADOS E DISCUSSÕES}

Curvas de Retenção de Água.

Os dados de umidade à base de volume $\left(\theta, \mathrm{cm}^{3} / \mathrm{cm}^{3}\right)$ das amostras encontram-se na Tabela 1. Esses valores de umidade referem-se aos potenciais 0 (saturado), $-1,-3,-8,-30,-100,-500$ e $-1500 \mathrm{kPa}$, que corresponde a $0,-10,-30,-80$, $300,-1000,-5000$ e $-15000 \mathrm{~cm}$ de água. A Figuras 02 mostra apenas as curvas de retenção de água referentes às amostras 01, 4III, 7 e 11. Para cada amostra são apresentadas duas curvas de retenção na seguinte forma: $\Psi \mathrm{m}$ ( $\mathrm{cm}$ de água) versus $\theta,\left(\mathrm{cm}^{3} / \mathrm{cm}^{3}\right)$ e $\mathrm{pF}$ versus $\theta\left(\mathrm{cm}^{3} / \mathrm{cm}^{3}\right)$; sendo $\mathrm{pF}=-\log$ $\Psi \mathrm{m}$. Nessas curvas o potencial mátrico está expresso em $\mathrm{cm}$ de água.

Pela Tabela 1 pode-se observar o comportamento das amostras de solo e de sedimento, no que se refere à capacidade de reter a água, que foi relativamente elevada, principalmente para as amostras de textura mais fina. Para as amostras 11, 12 e 13, que apresentaram uma textura com proporção de areia mais acentuada, mostraram-se com baixa capacidade de reter água, como era esperado. Estas amostras foram colhidas nos locais situados entre o paraná e o lago, sendo os solos com maior inclinação em relação aos outros locais amostrados. As composições granulométricas dessas amostras indicam que esses locais são os mais afetados pela erosão, pelos teores de argila mais baixos e de areia elevados.

Para fins agrícolas, toma-se tradicionalmente de $-30 \mathrm{kPa}$ no solo como sendo o potencial representativo da capacidade de campo, Para Prevedello (1996) é difícil estabelecer com precisão a capacidade de campo de um solo, pois tal condição é decorrente de um processo dinâmico, denominado de drenagem interna, também chamado de redistribuição da água no solo, que ocorre em regime transiente, onde a umidade e o potencial mátrico do solo variam no tempo e no espaço. Reichardt (1988) considera que a capacidade de campo é o resultado de um comportamento dinâmico da água no solo e não uma característica intrínseca de sua matriz, recomendando que o potencial deva ser mais alto e está entre $-0,06$ e $-0,1$ atmosfera (-6 e $-10 \mathrm{kPa})$.

$\mathrm{A}$ água retida pelo solo entre a capacidade de campo (CC) e o ponto de murcha permanente (PMP), é denominada de água disponível $(\mathrm{AD}$, $\mathrm{mm}$ ). O cálculo para estimar a água disponivel é dado pela equação (03), onde $\mathrm{h}$ é altura da camada do solo em consideração, no caso $10 \mathrm{~cm}$ :

A Tabela 2 fornece os valores de umidade referentes aos potenciais potenciais $-6,-10$ e $-30 \mathrm{kPa}$ (como capacidade de campo) e $-1500 \mathrm{kPa}$ (como o ponto de murcha permanente); da água disponível $(\mathrm{AD}, \mathrm{mm})$ entre cada umidade considerada na capacidade de campo. As umidades referentes aos potenciais -6 e $-10 \mathrm{kPa}$ foram estimadas utilizando a equação (1), com os valores fornecidos pelo ajuste dos dados pelo modelo de Van Genuchten (1980).

$\mathrm{AD}=(\mathrm{CC}-\mathrm{PMP}) \cdot 10 \mathrm{~h}$

Reichardt et al. (1980), estudaram 

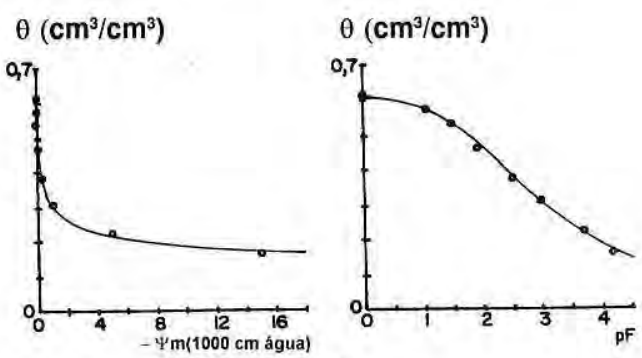

A
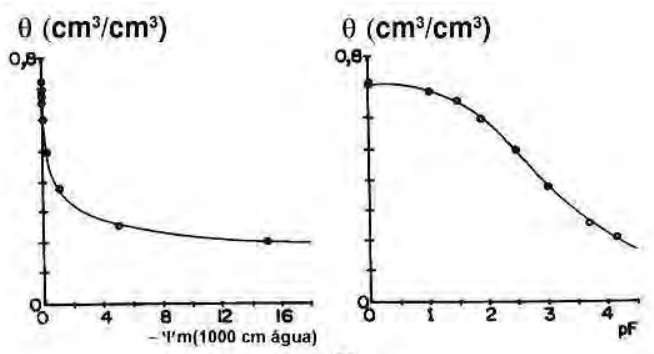

B
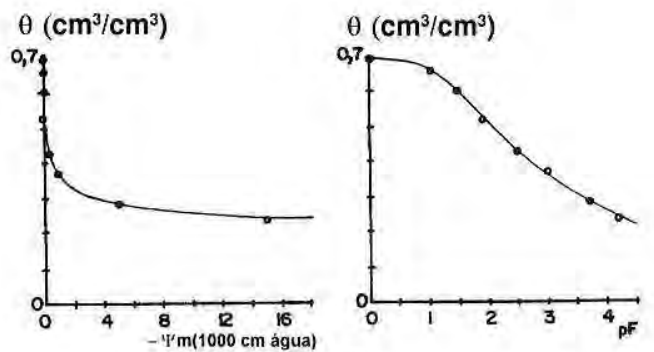

C
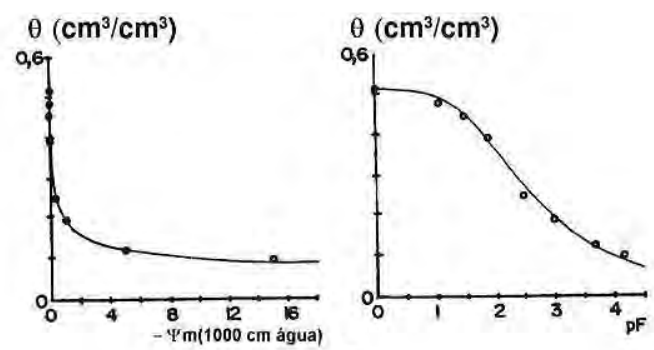

D

Figura 02. Curvas de retenção referentes às amostras (A) 1, (B) 4III, (C) 7 e (D) 11 . 
Tabela 1. Valores de umidade volumétrica $\left(\theta, \mathrm{cm}^{3} \cdot \mathrm{cm}^{-3}\right)$ para os oito potenciais mátricos $(\mathrm{kPa})$ utilizados.

\begin{tabular}{|c|c|c|c|c|c|c|c|c|}
\hline & 0 & -1 & -3 & -8 & -30 & -100 & -500 & -1500 \\
\hline 1 & 0,61 & 0,57 & 0,53 & 0,47 & 0,38 & 0,31 & 0,22 & 0,16 \\
\hline 2 & 0,64 & 0,61 & 0,58 & 0,52 & 0,43 & 0,36 & 0,28 & 0,21 \\
\hline 3 & 0,72 & 0,66 & 0,61 & 0,52 & 0,43 & 0,37 & 0,32 & 0,27 \\
\hline 4 & 0,68 & 0,64 & 0,60 & 0,53 & 0,37 & 0,31 & 0,23 & 0,20 \\
\hline 41 & 0,66 & 0,63 & 0,59 & 0,51 & 0,38 & 0,31 & 0,23 & 0,18 \\
\hline 411 & 0,66 & 0,62 & 0,58 & 0,52 & 0,37 & 0,28 & 0,21 & 0,17 \\
\hline $4 \mid I I$ & 0,72 & 0,69 & 0,66 & 0,60 & 0,50 & 0,38 & 0,25 & 0,21 \\
\hline 5 & 0,66 & 0,63 & 0,58 & 0,50 & 0,38 & 0,31 & 0,24 & 0,19 \\
\hline 51 & 0,67 & 0,63 & 0,58 & 0,52 & 0,39 & 0,32 & 0,24 & 0,19 \\
\hline 511 & 0,68 & 0,67 & 0,62 & 0,56 & 0,46 & 0,37 & 0,32 & 0,19 \\
\hline 5111 & 0,71 & 0,68 & 0,65 & 0,59 & 0,48 & 0,38 & 0,39 & 0,26 \\
\hline 6 & 0,71 & 0,67 & 0,64 & 0,58 & 0,49 & 0,41 & 0,38 & 0,30 \\
\hline 61 & 0,68 & 0,65 & 0,62 & 0,57 & 0,47 & 0,38 & 0,29 & 0,21 \\
\hline 611 & 0,69 & 0,67 & 0,65 & 0,60 & 0,50 & 0,41 & 0,36 & 0,22 \\
\hline 6III & 0,71 & 0,68 & 0,65 & 0,56 & 0,45 & 0,39 & 0,31 & 0,24 \\
\hline 7 & 0,70 & 0,66 & 0,60 & 0,52 & 0,43 & 0,37 & 0,28 & 0,23 \\
\hline 8 & 0,69 & 0,66 & 0,61 & 0,55 & 0,43 & 0,40 & 0,36 & 0,31 \\
\hline 9 & 0,71 & 0,65 & 0,58 & 0,48 & 0,36 & 0,29 & 0,22 & 0,20 \\
\hline 10 & 0,64 & 0,60 & 0,56 & 0,49 & 0,42 & 0,34 & 0,22 & 0,17 \\
\hline 11 & 0,54 & 0,52 & 0,50 & 0,45 & 0,31 & 0,16 & 0,10 & 0,08 \\
\hline 12 & 0,51 & 0,49 & 0,47 & 0,37 & 0,14 & 0,09 & 0,07 & 0,05 \\
\hline 13 & 0,52 & 0,48 & 0,45 & 0,39 & 0,25 & 0,19 & 0,12 & 0,10 \\
\hline 14 & 0,65 & 0,62 & 0,58 & 0,53 & 0,43 & 0,32 & 0,24 & 0,14 \\
\hline 141 & 0,66 & 0,63 & 0,60 & 0,55 & 0,45 & 0,30 & 0,18 & 0,15 \\
\hline $14 I I$ & 0,64 & 0,61 & 0,57 & 0,52 & 0,42 & 0,30 & 0,18 & 0,14 \\
\hline $14 I I I$ & 0,65 & 0,61 & 0,58 & 0,53 & 0,42 & 0,20 & 0,14 & 0,11 \\
\hline 15 & 0,65 & 0,61 & 0,58 & 0,53 & 0,46 & 0,36 & 0,23 & 0,18 \\
\hline 151 & 0,64 & 0,60 & 0,56 & 0,51 & 0,44 & 0,34 & 0,22 & 0,16 \\
\hline $15 I I$ & 0,63 & 0,60 & 0,56 & 0,50 & 0,43 & 0,35 & 0,24 & 0,19 \\
\hline $15 \mathrm{III}$ & 0,65 & 0,62 & 0,59 & 0,53 & 0,44 & 0,31 & 0,21 & 0,16 \\
\hline 16 & 0,67 & 0,63 & 0,59 & 0,54 & 0,46 & 0,37 & 0,27 & 0,20 \\
\hline 161 & 0,66 & 0,61 & 0,56 & 0,49 & 0,40 & 0,32 & 0,24 & 0,20 \\
\hline $16 \|$ & 0,68 & 0,64 & 0,60 & 0,54 & 0,46 & 0,38 & 0,26 & 0,20 \\
\hline 16111 & 0,67 & 0,64 & 0,61 & 0,55 & 0,46 & 0,40 & 0,32 & 0,25 \\
\hline 17 & 0,69 & 0,63 & 0,59 & 0,51 & 0,42 & 0,36 & 0,28 & 0,23 \\
\hline 18 & 0,69 & 0,65 & 0,60 & 0,51 & 0,41 & 0,36 & 0,28 & 0,22 \\
\hline 19 & 0,65 & 0,61 & 0,57 & 0,50 & 0,40 & 0,35 & 0,24 & 0,20 \\
\hline 20 & 0,69 & 0,67 & 0,62 & 0,56 & 0,47 & 0,46 & 0,38 & 0,31 \\
\hline
\end{tabular}


Tabela 2. Umidade volumétrica das amostras (am) referente aos potenciais mátricos $(\mathrm{kPa})-6$ $\left(\theta_{6}\right),-10\left(\theta_{10}\right),-30\left(\theta_{30}\right)$ e $-1500\left(\theta_{1500}\right)$; e água disponivel $(\mathrm{mm})$ na camada de $10 \mathrm{~cm}$ em relação às umidades $\theta_{6}\left(\mathbf{A D}_{6}\right), \theta_{10}\left(\mathbf{A D}_{10}\right), \theta_{30}\left(\mathbf{A D}_{30}\right)$.

\begin{tabular}{|c|c|c|c|c|c|c|c|}
\hline $\mathrm{Am}$ & $\theta_{6}$ & $\theta_{10}$ & $\theta_{30}$ & $\theta_{1500}$ & $A D_{6}$ & $A D_{10}$ & $A D_{30}$ \\
\hline 1 & 0,49 & 0,46 & 0,38 & 0,16 & 33 & 30 & 21 \\
\hline 2 & 0,54 & 0,51 & 0,43 & 0,21 & 32 & 29 & 21 \\
\hline 3 & 0,55 & 0,51 & 0,43 & 0,27 & 28 & 24 & 16 \\
\hline 4 & 0,54 & 0,49 & 0,37 & 0,20 & 34 & 30 & 18 \\
\hline 41 & 0,53 & 0,48 & 0,38 & 0,18 & 35 & 31 & 21 \\
\hline $4 I I$ & 0,52 & 0,48 & 0,37 & 0,17 & 35 & 30 & 19 \\
\hline 4111 & 0,62 & 0,59 & 0,50 & 0,21 & 41 & 38 & 29 \\
\hline 5 & 0,52 & 0,47 & 0,38 & 0,19 & 32 & 28 & 19 \\
\hline 51 & 0,53 & 0,49 & 0,39 & 0,19 & 34 & 30 & 20 \\
\hline 511 & 0,58 & 0,55 & 0,46 & 0,19 & 40 & 36 & 27 \\
\hline 5111 & 0,60 & 0,57 & 0,48 & 0,26 & 35 & 31 & 23 \\
\hline 6 & 0,59 & 0,56 & 0,49 & 0,30 & 29 & 26 & 19 \\
\hline 61 & 0,59 & 0,56 & 0,47 & 0,21 & 38 & 34 & 26 \\
\hline 611 & 0,62 & 0,58 & 0,50 & 0,22 & 40 & 36 & 28 \\
\hline 6III & 0,55 & 0,51 & 0,45 & 0,24 & 30 & 27 & 21 \\
\hline 7 & 0,56 & 0,53 & 0,43 & 0,23 & 32 & 29 & 19 \\
\hline 8 & 0,50 & 0,46 & 0,43 & 0,31 & 19 & 15 & 12 \\
\hline 9 & 0,52 & 0,49 & 0,36 & 0,20 & 32 & 29 & 16 \\
\hline 10 & 0,47 & 0,42 & 0,42 & 0,17 & 29 & 25 & 24 \\
\hline 11 & 0,39 & 0,31 & 0,31 & 0,08 & 31 & 23 & 23 \\
\hline 12 & 0,40 & 0,36 & 0,14 & 0,05 & 35 & 30 & 09 \\
\hline 13 & 0,59 & 0,55 & 0,25 & 0,10 & 49 & 45 & 15 \\
\hline 14 & 0,55 & 0,52 & 0,43 & 0,14 & 41 & 38 & 30 \\
\hline 141 & 0,57 & 0,53 & 0,45 & 0,15 & 42 & 38 & 30 \\
\hline $14 I I$ & 0,54 & 0,50 & 0,42 & 0,14 & 39 & 36 & 27 \\
\hline $14 I I I$ & 0,55 & 0,50 & 0,42 & 0,11 & 44 & 40 & 31 \\
\hline 15 & 0,55 & 0,52 & 0,46 & 0,18 & 37 & 35 & 28 \\
\hline 151 & 0,53 & 0,51 & 0,44 & 0,16 & 38 & 35 & 28 \\
\hline $15 I I$ & 0,52 & 0,50 & 0,43 & 0,19 & 34 & 31 & 24 \\
\hline $15 \mathrm{III}$ & 0,55 & 0,52 & 0,44 & 0,16 & 39 & 36 & 28 \\
\hline 16 & 0,56 & 0,53 & 0,46 & 0,20 & 35 & 33 & 25 \\
\hline 161 & 0,51 & 0,48 & 0,40 & 0,20 & 32 & 28 & 21 \\
\hline $16 \|$ & 0,56 & 0,53 & 0,46 & 0,20 & 36 & 33 & 26 \\
\hline $16 \| 11$ & 0,57 & 0,54 & 0,46 & 0,25 & 32 & 29 & 21 \\
\hline 17 & 0,54 & 0,50 & 0,42 & 0,23 & 30 & 27 & 19 \\
\hline 18 & 0,53 & 0,50 & 0,41 & 0,22 & 31 & 27 & 19 \\
\hline 19 & 0,52 & 0,49 & 0,40 & 0,20 & 33 & 29 & 21 \\
\hline 20 & 0,58 & 0,55 & 0,47 & 0,31 & 26 & 23 & 16 \\
\hline
\end{tabular}


características fisicas de alguns solos de terra firme próximos à Manaus e verificaram que esses solos, em média, têm baixa capacidade de reter a água. $\mathrm{O}$ valor médio obtido para a camada de $30 \mathrm{~cm}$ de $19,7 \mathrm{~mm}$, correspondendo a $6,6 \mathrm{~mm}$ para a camada de $10 \mathrm{~cm}$. Estimaram como água disponivel $(\mathrm{AD})$ a água retida pelo solo, entre os potenciais -30 e $-1500 \mathrm{kPa}$.

O valor mais baixo obtido, considerando o potencial $-30 \mathrm{kPa}$ foi $9 \mathrm{~mm}$ (amostra 12) e o mais elevado foi $31 \mathrm{~mm}$ (amostra 14III). Portanto os valores obtidos indicam que essas amostras apresentam capacidade de retenção mais elevada do que os solos estudados por Reichardt et al. (1980).

Corrêa (1989), registrou valores de umidade volumétrica correspondendo aos potenciais $-10 \mathrm{e}-1500 \mathrm{kPa}$ em áreas de floresta e de pastos em regiões de terra-firme próximas à Manaus. Os seus resultados para a camada de $0-10$ $\mathrm{cm}$ variaram para o potencial -10 de 43,5 a 59,0 (em \% de volume) estando esses valores de umidade na mesma faixa dos resultados obtidos nos lagos Passarinho e Gravetão, fazendo exceção as amostras 11, 12 e 13 que apresentaram uma textura mais grossa. Comparando os resultados obtidos por Corrêa (1989), seus dados de umidade referentes ao potencial $1500 \mathrm{kPa}$, que variaram de 26,6 a 33,0 (em \% de volume), verifica-se que estes foram mais elevados. A água disponivel, considerando o potencial mais elevado $(-10 \mathrm{kPa})$ como a capacidade de campo, apresentou valores mais baixos (variaram de 16,9 a $26 \mathrm{~mm}$ de água) do que grande parte das amostras, o que pode ser visto observando a Tabela 2. Essa capacidade de retenção de água relativamente elevada mostra que esses solos de várzea amostrados, podem dispor de mais água para as plantas em relação aos solos de terra-firme. Os dados de água disponivel fornecidos por Ferreira et al. (1995), obtidos em floresta de terra-firme intacta e manejada para a camada de solo 0-5 $\mathrm{cm}$, variaram de 13,88 a $12,01 \mathrm{~mm}$, são mais baixos do que os fornecidos neste trabalho. Essas altas capacidade de armazenar água também dificultam o escoamento superficial, durante as precipitações.

Os solos de várzea por serem os mais baixos da região, podem apresentar nas épocas de alto nível d'água, pela proximidade do lençol freático, condições elevadas de umidade. Porém, na época de baixo nivel da água, em práticas agrícolas onde as plantas apresentem raizes com baixa profundidade, a camada do solo superficial pode apresentar baixo armazenamento d'água e, no caso de se pretender a irrigação, pode-se recorrer a instalação de tensiômetros, que fornecem o potencial mátrico do solo e, indiretamente, com a curva característica de retenção de água, estimar a umidade do solo, tornando assim a utilização desses solos mais eficiente. Além do estudo da capacidade de armazenamento da água, é importante a determinação da condutividade hidráulica do solo saturado e em condições insaturado, para o melhor entendimento da dinâmica da água nesses solos. 
Densidade de Partículas, Coeficiente de Atenuação de Massa, Densidade Global (ou Aparente) e Porosidade Total

$\mathrm{Na}$ Tabela 3 são apresentados os resultados de densidade de partículas $\left(\rho_{\mathrm{p}}, \mathrm{g} / \mathrm{cm}^{3}\right)$, coeficiente de atenuação de massa $\left(\mu_{\mathrm{p}}, \mathrm{cm}^{2} / \mathrm{g}\right)$. Estes dados são utilizados na equação (2) para a obtenção dos valores dos componentes da composição granulométrica. Estão também os resultados de densidade global ou aparente $\left(\rho_{\mathrm{g}}, \mathrm{g} / \mathrm{cm}^{3}\right)$ e porosidade $\left(\phi, \mathrm{cm}^{3} / \mathrm{cm}^{3}\right)$. A porosidade, que também é denominada de volume total de poros, e a partir da Tabela 3, é possivel verificar que os valores mais baixos foram fornecidos pelas amostras que apresentaram os teores mais elevados de areia, como as amostras $(11,12$ e 13).

\section{Análise Granulométreica}

Os valores de percentagem correspondentes às frações de argila, silte e areia, obtidos pelo método da atenuação gama (M.A.G.), são apresentados através da Tabela 4. Com esses resultados as amostras foram classificadas de acordo com a sua textura, utilizando os resultados obtidos pelo método da atenuação gama.

Com exceção da amostra $n^{\circ} 12$, que forneceu o valor mais elevado de areia $(80 \%)$, a fração silte foi a que se apresentou em maior proporção, seguida da fração argila. No lago Passarinho as frações variaram de 49 a $71 \%$ para silte, 8 a 42 $\%$ para argila e 2 a $29 \%$ para areia. No lago Gravetão as frações oscilaram entre $17 \mathrm{e}$ $70 \%, 3$ e $45 \%, 0$ e $80 \%$, respectivamente a silte, argila e areia.

Com os resultados correspondentes às frações de argila, silte e areia, as amostras foram classificadas de acordo com a sua textura, cujas classes encontram-se na Tabela 5. Foi empregado o triângulo proposto pelo Soil Survey Staff do departamento de Agricultura dos estados Unidos da América do Norte, modificado pela Sociedade Brasileira de Ciência do Solo.

A fração silte, da composição granulométrica da maioria das amostras, foi a mais elevada seguida da argila e areia, em ambos os lagos. No lago Passarinho a classe textural franco argilo siltoso foi a mais frequente para o solo e o sedimento. No Gravetão a classe textural mostrou-se mais variada. No sedimento a mais frequente foi a franco silto e para o solo a franco argilo siltoso.

Os solos mais baixos da várzea sofrem inundação anual, possuindo uma fase onde o solo encontra-se saturado com a água e nas áreas abertas e protegidas de corrente, as macrófitas aquáticas desenvolvem-se mais intensamente. Quando o nível d'água começa a diminuir, parte das macrófitas morre e pelas características físicas dos solos amostrados, a água de chuva deve tender a escoar mais superficialmente do que por drenagem interna, facilitanto a retirada de materiais solúveis e de partículas para os lagos. Era esperado observar uma proporção mais elevada de argila no sedimento, mas não foi isso revelado, o que se observou foram dados variados, como pode-se observar analisando a Tabela 4. Também era esperado uma diminuição do teor de argila no perfil do sedimento devido aos processos de sedimentação, no qual as particulas com maiores diâmetros decantam primeiro. 
características físicas de alguns solos de terra firme próximos à Manaus e verificaram que esses solos, em média, têm baixa capacidade de reter a água. $\mathrm{O}$ valor médio obtido para a camada de $30 \mathrm{~cm}$ de $19,7 \mathrm{~mm}$, correspondendo a $6,6 \mathrm{~mm}$ para a camada de $10 \mathrm{~cm}$. Estimaram como água disponivel (AD) a água retida pelo solo, entre os potenciais $-30 \mathrm{e}-1500 \mathrm{kPa}$.

$\mathrm{O}$ valor mais baixo obtido, considerando o potencial $-30 \mathrm{kPa}$ foi $9 \mathrm{~mm}$ (amostra 12) e o mais elevado foi $31 \mathrm{~mm}$ (amostra 14III). Portanto os valores obtidos indicam que essas amostras apresentam capacidade de retenção mais elevada do que os solos estudados por Reichardt et al. (1980).

Corrêa (1989), registrou valores de umidade volumétrica correspondendo aos potenciais $-10 \mathrm{e}-1500 \mathrm{kPa}$ em áreas de floresta e de pastos em regiões de terra-firme próximas à Manaus. Os seus resultados para a camada de $0-10$ $\mathrm{cm}$ variaram para o potencial -10 de 43,5 a 59,0 (em \% de volume) estando esses valores de umidade na mesma faixa dos resultados obtidos nos lagos Passarinho e Gravetão, fazendo exceção as amostras 11,12 e 13 que apresentaram uma textura mais grossa. Comparando os resultados obtidos por Corrêa (1989), seus dados de umidade referentes ao potencial $1500 \mathrm{kPa}$, que variaram de 26,6 a 33,0 (em \% de volume), verifica-se que estes foram mais elevados. A água disponível, considerando o potencial mais elevado $(-10 \mathrm{kPa})$ como a capacidade de campo, apresentou valores mais baixos (variaram de 16,9 a $26 \mathrm{~mm}$ de água) do que grande parte das amostras, o que pode ser visto observando a Tabela 2. Essa capacidade de retenção de água relativamente elevada mostra que esses solos de várzea amostrados, podem dispor de mais água para as plantas em relação aos solos de terra-firme. Os dados de água disponivel fornecidos por Ferreira et al. (1995), obtidos em floresta de terra-firme intacta e manejada para a camada de solo $0-5$ $\mathrm{cm}$, variaram de 13,88 a $12,01 \mathrm{~mm}$, são mais baixos do que os fornecidos neste trabalho. Essas altas capacidade de armazenar água também dificultam o escoamento superficial, durante as precipitações.

Os solos de várzea por serem os mais baixos da região, podem apresentar nas épocas de alto nível d'água, pela proximidade do lençol freático, condições elevadas de umidade. Porém, na época de baixo nivel da água, em práticas agrícolas onde as plantas apresentem raizes com baixa profundidade, a camada do solo superficial pode apresentar baixo armazenamento d'água e, no caso de se pretender a irrigação, pode-se recorrer a instalação de tensiômetros, que fornecem o potencial mátrico do solo e, indiretamente, com a curva característica de retenção de água, estimar a umidade do solo, tornando assim a utilização desses solos mais eficiente. Além do estudo da capacidade de armazenamento da água, é importante a determinação da condutividade hidráulica do solo saturado e em condições insaturado, para o melhor entendimento da dinâmica da água nesses solos. 
Tabela 3. Densidade de particula $\left(\rho_{\mathrm{p}}, \mathrm{g} / \mathrm{cm}^{3}\right)$, coeficiente de atenuação de massa $\left(\mu_{\mathrm{p}}, \mathrm{m}^{2} / \mathrm{g}\right)$ densidade global $\left(\rho_{\mathrm{g}}, \mathrm{g} / \mathrm{cm}^{3}\right)$ e porosidade total $\left(\phi, \mathrm{cm}^{3} / \mathrm{cm}^{3}\right)$.

\begin{tabular}{|c|c|c|c|c|}
\hline AMOSTRA & $\rho_{p}$ & $\mu_{\mathrm{p}}$ & $\rho_{g}$ & $\phi$ \\
\hline 1 & 2,64 & 0,31 & 1,05 & 0,61 \\
\hline 2 & 2,55 & 0,31 & 1,01 & 0,64 \\
\hline 3 & 2,60 & 0,31 & 0,87 & 0,72 \\
\hline 4 & 2,68 & 0,32 & 0,80 & 0,68 \\
\hline 41 & 2,70 & 0,32 & 0,83 & 0,66 \\
\hline 411 & 2,65 & 0,30 & 0,80 & 0,66 \\
\hline $4 I I I$ & 2,59 & 0,30 & 0,94 & 0,72 \\
\hline 5 & 2,66 & 0,31 & 0,82 & 0,66 \\
\hline 51 & 2,63 & 0,31 & 0,84 & 0,67 \\
\hline 511 & 2,69 & 0,30 & 0,89 & 0,68 \\
\hline 5111 & 2,71 & 0,33 & 0,93 & 0,71 \\
\hline 6 & 2,66 & 0,32 & 0,95 & 0,71 \\
\hline 61 & 2,67 & 0,33 & 0,95 & 0,68 \\
\hline 611 & 2,67 & 0,31 & 0,99 & 0,69 \\
\hline 6III & 2,58 & 0,32 & 0,89 & 0,71 \\
\hline 7 & 2,64 & 0,31 & 1,07 & 0,70 \\
\hline 8 & 2,53 & 0,31 & 1,02 & 0,69 \\
\hline 9 & 2,43 & 0,31 & 0,82 & 0,71 \\
\hline 10 & 2,68 & 0,33 & 0,99 & 0,64 \\
\hline 11 & 2,62 & 0,29 & 1,21 & 0,54 \\
\hline 12 & 2,67 & 0,29 & 1,31 & 0,51 \\
\hline 13 & 2,69 & 0,31 & 0,84 & 0,52 \\
\hline 14 & 2,52 & 0,30 & 1,05 & 0,65 \\
\hline 141 & 2,64 & 0,32 & 0,98 & 0,66 \\
\hline $14 \|$ & 2,65 & 0,32 & 1,00 & 0,64 \\
\hline 14111 & 2,64 & 0,30 & 1,04 & 0,65 \\
\hline 15 & 2,64 & 0,31 & 1,03 & 0,65 \\
\hline 151 & 2,70 & 0,33 & 0,87 & 0,64 \\
\hline $15 \mathrm{II}$ & 2,76 & 0,31 & 0,89 & 0,63 \\
\hline $15 I I I$ & 2,60 & 0,31 & 0,99 & 0,65 \\
\hline 16 & 2,85 & 0,31 & 0,90 & 0,67 \\
\hline 161 & 2,69 & 0,31 & 0,78 & 0,66 \\
\hline $16 \|$ & 2,69 & 0,32 & 0,92 & 0,68 \\
\hline $16 I I I$ & 2,59 & 0,31 & 0,99 & 0,67 \\
\hline 17 & 2,56 & 0,31 & 0,84 & 0,69 \\
\hline 18 & 2,63 & 0,31 & 0,83 & 0,69 \\
\hline 19 & 2,61 & 0,32 & 0,94 & 0,65 \\
\hline 20 & 2,65 & 0,31 & 0,97 & 0,69 \\
\hline
\end{tabular}


Tabela 4. Composição granulométrica (\%) obtida pelo método da atenuação gama.

\begin{tabular}{|c|c|c|c|}
\hline AMOSTRA & ARGILA & SILTE & AREIA \\
\hline 1 & 26 & 68 & 6 \\
\hline 2 & 31 & 59 & 10 \\
\hline 3 & 26 & 60 & 14 \\
\hline 4 & 32 & 59 & 9 \\
\hline 41 & 30 & 63 & 7 \\
\hline $4 I I$ & 32 & 58 & 10 \\
\hline 4III & 20 & 71 & 9 \\
\hline 5 & 31 & 61 & 8 \\
\hline 51 & 33 & 63 & 4 \\
\hline 511 & 38 & 60 & 2 \\
\hline $5 \mathrm{III}$ & 8 & 63 & 29 \\
\hline 6 & 30 & 64 & 6 \\
\hline 61 & 32 & 61 & 7 \\
\hline 611 & 33 & 57 & 10 \\
\hline 6III & 25 & 70 & 5 \\
\hline 7 & 42 & 49 & 9 \\
\hline 8 & 36 & 54 & 10 \\
\hline 9 & 27 & 57 & 16 \\
\hline 10 & 25 & 58 & 17 \\
\hline 11 & 10 & 35 & 55 \\
\hline 12 & 3 & 17 & 80 \\
\hline 13 & 12 & 48 & 40 \\
\hline 14 & 21 & 63 & 16 \\
\hline 141 & 17 & 61 & 22 \\
\hline $14 \|$ & 15 & 59 & 26 \\
\hline 14III & 5 & 56 & 39 \\
\hline 15 & 22 & 67 & 11 \\
\hline 151 & 20 & 70 & 10 \\
\hline 1511 & 28 & 64 & 81 \\
\hline 5111 & 16 & 67 & 17 \\
\hline 16 & 25 & 70 & 5 \\
\hline $16 I$ & 30 & 66 & 4 \\
\hline $16 \|$ & 35 & 65 & 0 \\
\hline $16 I I I$ & 27 & 62 & 11 \\
\hline 17 & 33 & 58 & 9 \\
\hline 18 & 45 & 47 & 8 \\
\hline 19 & 30 & 57 & 13 \\
\hline 20 & 25 & 62 & 13 \\
\hline
\end{tabular}


Tabela 5. Classificação textural.

\begin{tabular}{|c|c|c|c|}
\hline AMOSTRA & CLASSE TEXTURAL & AMOSTRA & CLASSE TEXTURAL \\
\hline 1 & franco argilo siltoso & 11 & franco arenoso \\
\hline 2 & franco argilo siltoso & 12 & areia franco \\
\hline 3 & franco argilo siltoso & 13 & franco \\
\hline 4 & franco argilo siltoso & 14 & franco siltoso \\
\hline 41 & franco argilo siltoso & 141 & franco siltoso \\
\hline 411 & franco argilo siltoso & 1411 & franco siltoso \\
\hline 4111 & franco siltoso & $14 I I I$ & franco siltoso \\
\hline 5 & franco argilo siltoso & 15 & franco siltoso \\
\hline 51 & franco argilo siltoso & 151 & franco siltoso \\
\hline 511 & franco argilo siltoso & 1511 & franco siltoso \\
\hline 5111 & franco siltoso & $15 I I I$ & franco siltoso \\
\hline 6 & franco argilo siltoso & 16 & franco siltoso \\
\hline 61 & franco argilo siltoso & 161 & franco argilo siltoso \\
\hline 611 & franco argilo siltoso & $16 \|$ & argila siltosa \\
\hline 6111 & franco argilo siltoso & 16111 & franco argilo siltoso \\
\hline 7 & argila siltosa & 17 & franco argilo siltoso \\
\hline 8 & franco argilo siltoso & 18 & argila siltosa \\
\hline 9 & franco argilo siltoso & 19 & franco argilo siltoso \\
\hline 10 & franco siltoso & 20 & franco argilo siltoso \\
\hline
\end{tabular}

\section{CONCLUSÕES}

Os resultados dos parâmetros físicos investigados em amostras de solos e de sedimentos de dois lagos de várzea, Passarinho e Gravetão, nos permite concluir que:

Os resultados indicaram capacidade elevada de armazenar água, principalmente as amostras com os teores mais elevados de argila. O valor mais baixo obtido , considerando o potencial $-30 \mathrm{kPa}$ foi $9 \mathrm{~mm}$ e o mais elevado foi $31 \mathrm{~mm}$. Portanto esses valores indicam que essas amostras apresentam capacidade de retenção mais elevada do que solos de terra firme.

A fração silte, da composição granulométrica da maioria das amostras, foi a mais elevada seguida da argila e areia, em ambos os lagos. No lago Passarinho a classe textural franco argilo siltoso foi a mais frequente para o solo e o sedimento. No Gravetão a classe textural mostrou-se mais variada. No sedimento a mais frequente foi a franco silto e para o solo a franco argilo siltoso.

\section{AGRADECIMENTOS}

Ao Convênio INPA - Instituto Max Planck - Projeto: estudos dos Sistemas de ocupação das Várzeas do Médio rio Amazonas, pelo apoio logístico durante as coletas

A Luiz Vilmar Souza da Silva, da Coordenação de Pesquisas em Geociências/INPA, pelo apoio durante as coletas.

Aos moradores dos lagos, que nos permitiram realizar as coletas. No lago Gravetão, Maria de Nazaré Inhamuns de Paula, Flávio Pinto da Costa (major) e Antonia Edina Paula da Costa, além de nos 
Tabela 5. Classificação textural.

\begin{tabular}{llcl}
\hline AMOSTRA & CLASSE TEXTURAL & AMOSTRA & CLASSE TEXTURAL \\
\hline 1 & franco argilo siltoso & 11 & franco arenoso \\
2 & franco argilo siltoso & 12 & areia franco \\
3 & franco argilo siltoso & 13 & franco \\
4 & franco argilo siltoso & 14 & franco siltoso \\
$4 \mathrm{II}$ & franco argilo siltoso & $14 \mathrm{I}$ & franco siltoso \\
$4 \mathrm{II}$ & franco argilo siltoso & $14 \mathrm{II}$ & franco siltoso \\
$4 \mathrm{III}$ & franco siltoso & $14 \mathrm{II}$ & franco siltoso \\
5 & franco argilo siltoso & 15 & franco siltoso \\
$5 \mathrm{I}$ & franco argilo siltoso & $15 \mathrm{I}$ & franco siltoso \\
$5 \mathrm{II}$ & franco argilo siltoso & $15 \mathrm{II}$ & franco siltoso \\
$5 \mathrm{III}$ & franco siltoso & $15 \mathrm{III}$ & franco siltoso \\
6 & franco argilo siltoso & 16 & franco siltoso \\
$6 \mathrm{I}$ & franco argilo siltoso & $16 \mathrm{I}$ & franco argilo siltoso \\
$6 \mathrm{II}$ & franco argilo siltoso & $16 \mathrm{II}$ & argila siltosa \\
$6 \mathrm{III}$ & franco argilo siltoso & $16 \mathrm{III}$ & franco argilo siltoso \\
7 & argila siltosa & 17 & franco argilo siltoso \\
8 & franco argilo siltoso & 18 & argila siltosa \\
9 & franco argilo siltoso & 19 & franco argilo siltoso \\
10 & franco siltoso & 20 & franco argilo siltoso \\
\hline
\end{tabular}

\section{CONCLUSÕES}

Os resultados dos parâmetros físicos investigados em amostras de solos e de sedimentos de dois lagos de várzea, Passarinho e Gravetão, nos permite concluir que:

Os resultados indicaram capacidade elevada de armazenar água, principalmente as amostras com os teores mais elevados de argila. $\mathrm{O}$ valor mais baixo obtido, considerando o potencial $-30 \mathrm{kPa}$ foi $9 \mathrm{~mm}$ e o mais elevado foi $31 \mathrm{~mm}$. Portanto esses valores indicam que essas amostras apresentam capacidade de retenção mais elevada do que solos de terra firme.

A fração silte, da composição granulométrica da maioria das amostras, foi a mais elevada seguida da argila e areia, em ambos os lagos. No lago Passarinho a classe textural franco argilo siltoso foi a mais frequente para o solo e o sedimento. No Gravetão a classe textural mostrou-se mais variada. No sedimento a mais frequente foi a franco silto e para o solo a franco argilo siltoso.

\section{AGRADECIMENTOS}

Ao Convênio INPA - Instituto Max Planck - Projeto: estudos dos Sistemas de ocupação das Várzeas do Médio rio Amazonas, pelo apoio logistico durante as coletas

A Luiz Vilmar Souza da Silva, da Coordenação de Pesquisas em Geociências/INPA, pelo apoio durante as coletas.

Aos moradores dos lagos, que nos permitiram realizar as coletas. No lago Gravetão, Maria de Nazaré Inhamuns de Paula, Flávio Pinto da Costa (major) e Antonia Edina Paula da Costa, além de nos 
permitir coletar as amostras, ajudaram-nos com informações e canoa.

\section{Bibliografia citada}

Corrêa, J. C. 1989. Avaliação da degradação de pasto em um latossolo amarelo da Amazônia Central. Tese de Doutorado - Escola Superior de Agricultura "Luiz de Queiroz", Universidade de São Paulo. Piracicaba. 111p. Dourado-Neto, D;; Van Lier, Q. J. ; Botrel, T. A; Libardi, P. L. 1990. Programa para confecção da curva de retenção da água no solo utilizando o modelo de Genuchten. Eng. Rural, Piracicaba, 1(2):94-11.

Empresa Brasileira de Pesquisa Agropecuária. 1979. Serviço Nacional de Levantamento e Conservação de Solos, Rio de Janeiro, R, J.Manual de métodos de análises I. p. 229

Ferreira, S, J, F.; Crestana, S.; Ross, S. M.; Mello, W.; Luizão, F. J. 1995. A influência do manejo florestal nas características físicas do solo em uma área de floresta de terra firme na Amazônia Central. Anais do XXIII Congresso Brasileiro de sistema Particulados. Vol 2, p. 1043-1050.

Junk, W. J. 1980. Áreas inundáveis - um desafio para a limnologia. Acta Amazonica, 10 (4): 775-795.

JunK, W. J.; Bayley, P. B.; Sparks, R. E. 1989. The flood pulse concept in river-floodplain systems. In: Dodge, D. P. (Ed). Proceedings of the International Large River Symposium. Can Spec. Publ. Fish. Aquat. Sci. 106. p.110-127.

Junk. W. J. 1995. Capacidade de suporte de ecossistemas: Amazônia como estudo de caso. In: Tauk-Tornisielo, S. M.; Gobbi, N,; Foresti, C.; Lima, S. T. (Eds). Análise Ambiental: estratégias e ações. T. A. Centro de Estudos Ambientais - Universidade Estadual Paulista (UNESP). Rio Claro, São Paulo, p.51-63.

Likens, G. E. 1984. Edgardo Baldi Memorial lecture. Beyond the Shoreline: a watershed - ecosystem approach. Ver: International Verrein. Limnol., Stuttgard. 22:1-22.

Meade, R. H.; Nordin Jr., C. F.; Curtis, W. F.; Rodrigues, F. M. C.; Vale, C. M.; Edmond, J. M. 1979. Transporte de sedimentos no rio Amazonas. Acta Amazonica, 9(3): 543-547.
Odum, E. P. 1988. Ecologia. Trad. por Christopher J. Tribe. Rio de Janeiro, Guanabara. 434p.

Prevedello, C. L. 1996. Fisica do solo com problemas resolvidos. Curitiba. SAEAFS. $446 p$.

Reichardt, K; Ranzani, G; Freitas Jr, E. de; Libardi, P. L. 1980. Aspectos hídricos de alguns solos da Amazônia - Região do baixo rio Negro. Acta Amazonica. 10 (1) :43-46.

Reichardt, K. 1988. Capacidade de campo. Revista Brasilerira de Ciència do Solo. n. 12, p 211-216.

Ribeiro, A. 1991. Análise das variaçōes climáticas observadas na região de Manaus (AM). Dissertação de Mestrado, Escola Superior de Agricultura "Luiz de Queiroz", Universidade de São Paulo. Piracicaba, São Paulo. 131p.

Schubart, H. O. R. 1983. Ecologia e utilização das florestas In: Salati, E.; Junk, W. J.; Schubart, H. O. R; Oliveira, A. (Eds.) Amazônia, Desenvolvimento, Integração e ecologia. São Paulo, brasiliense. p. 101-143.

Sioli, H. 1984. The Amazon and its main affluents: Hydrography, morphology of the river courses and river types. In: Sioli, H., ED. The Amazon limnology and landscape ecology of a might tropical river and its basin. Dordrecht, Dr. W Junk Publishers. p. 127-165.

Sioli, H. 1985. Amazônia - Fundamentos da ecologia da maior região de florestas tropicais. Trad. J. Becker. Rio de Janeiro, Vozes, $72 \mathrm{p}$

Van Genuchten, M. 1980. A closed-form equation for predicting the hidraulic conductivity of unsaturated soils. Soil Science Society of American Journal, Madison. n. 44, p 892-898.

Van Lier, Q. J.; Dourado-Neto, D. 1991. Programa "CURVARET', VERSÃO 2.11. Escola Superior de Agricultura "Luiz de Queiroz"/ Universidade de São Paulo. Piracicaba.

Vaz, C. M. P.; Oliveira, J. C. M.; Reichardt, K; Crestana, S.; Cruvinel, P. E.; Bacchi, O. O. S. 1992. Soil Mechanical through Gamma Ray Attenuation. Soil technology, 5: 319-325.

Vieira, L. S. e Santos, P. C. T. C dos. 1987. Amazônia seus solos e outros recursos naturais. São Paulo, Agronômica Ceres. 416p.

\section{Aceito para publicação em 14.10.98}

